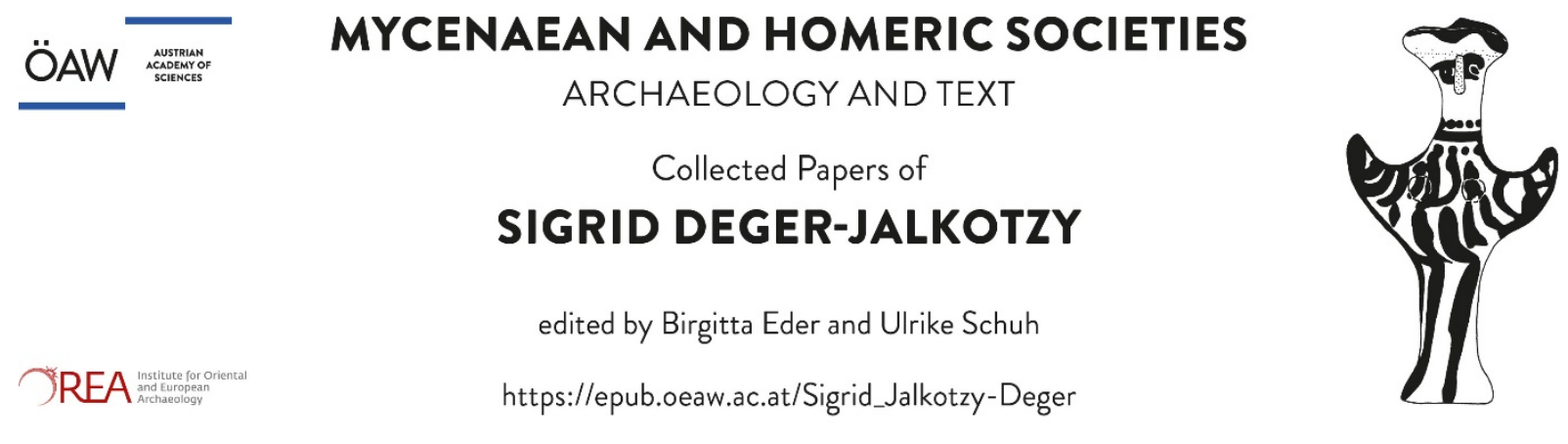

17.

S. Deger-Jalkotzy

Nachruf auf Fritz Schachermeyr

Kadmos 29, 1990, 89-91

(C) W. de Gruyter

DOI: https://doi.org/10.1515/kadm.1990.29.2.88

https://www.degruyter.com/view/j/kadm

mit freundlicher Genehmigung / with kind permission

Dieses Dokument darf ausschließlich für wissenschaftliche Zwecke genutzt werden (Lizenz CC BY-NC-ND), gewerbliche Nutzung wird urheberrechtlich verfolgt.

This document is for scientific use only (license CC BY-NC-ND), commercial use of copyrighted material will be prosecuted. 

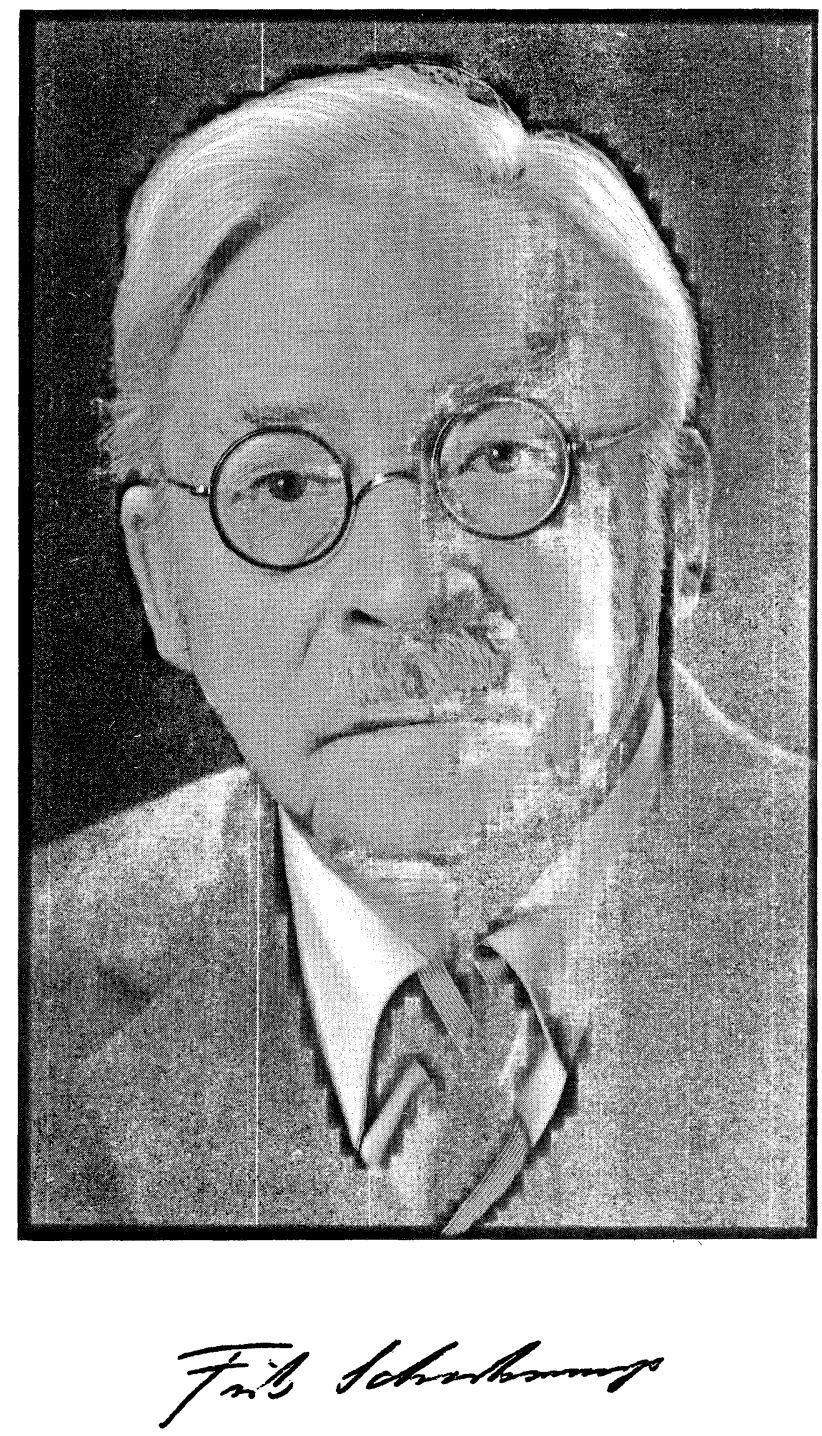

Foto: Begsteiger, Linz 


\section{FRITZ SCHACHERMEYR †}

\section{Januar 1895 - 26. Dezember 1987}

Es ist kein Zufall, daß nicht nur die Vertreter der althistorischen Fachdisziplin um Fritz Schachermeyr trauerten, als er kurz vor Vollendung seines 93. Lebensjahres starb. Nachrufe und andere Zeichen des Gedenkens, die in den Publikationsorganen der Fachwissenschaften Archäologie, Klassische Philologie, Altorientalistik, aber ebenso auch der sogenannten Ganzheitsforschung erschienen sind, zeugen von der Bewunderung und Anerkennung, die dieser vielleicht letzte große Universalhistoriker des Altertums für seine außerordentlichen Verdienste und für seine weitreichende, interdisziplinäre Fachkompetenz fand.

Fritz Schachermeyr machte sich zudem auf dem Gebiet der ägäischen Sprachen und Inschriften in hohem Maße verdient. Wenn er auch nicht so sehr selbst als Linguist und Epigraphiker hervortrat, so verlieh er der Forschung oftmals wesentliche Impulse und wies ihr den richtigen Weg. Dazu befähigte ihn zunächst seine profunde Ausbildung in den Sprachen der Alten Welt. Auf dem Gymnasium entwickelte er für das Griechische eine so große Vorliebe, $\mathrm{da}$ er vom sechzehnten Lebensjahr an alle Texte mühelos im Original lesen konnte. Auch für die Keilschriftkulturen regte sich das Interesse des Gymnasiasten, so daß er sich diese Schrift samt den Grundkenntnissen des Assyrischen selbst beibrachte. Ganz natürlich galten daher Schachermeyrs Universitätsstudien in Graz, Berlin und Innsbruck der Geschichte Griechenlands und der Altorientalistik. Seine Innsbrucker Dissertation handelte über „Ägypten der 18. und 19. Dynastie in seinen Beziehungen zu Ägäis und Vorderasien“ (1921). Er betätigte sich aber auch auf dem Gebiet der Epigraphik. Ein bereits weit fortgeschrittenes Habilitationsprojekt, das in der Neu-Herausgabe der Attischen Tributlisten hätte bestehen sollen, mußte er aufgeben, als die Amerikaner im Zuge der Agora-Ausgrabungen dieselbe Aufgabe in großem Stil übernahmen. Wohl nur wenigen dürfte ferner bekannt sein, daß Fritz Schachermeyr Mitherausgeber der beiden ersten Hälften des Corpus Inscriptionum Chaldicarum war. Ausgewiesen im Griechischen, Lateinischen, Ägyptischen und in der Assyriologie, und erfahren im Umgang mit epigraphischem Material, entwikkelte er, über die quellenkundliche Behandlung von Texten und Inschriften hinaus, ein feines Gefühl für sprachliche Strukturen, für Schriftsysteme und schließlich auch für vergleichende Sprachforschung. Während seiner Studien in Innsbruck hatte er bei A. Walde gehört, und als Ordinarius in Wien pflegte er enge Kontakte zu Paul Kretschmer, den er zeitlebens verehrte.

Weltbekannt und in der Weite seines Wissens unerreicht war Fritz Schachermeyr auf dem Gebiet der archäologischen Erforschung der frühen Kulturen 
Griechenlands. Über sechzig Jahre seines Lebens beschäftigte er sich mit der Aufarbeitung des Fundmaterials der minoischen und der mykenischen Hochkulturen, doch ebenso mit den prähistorischen Perioden des östlichen Mittelmeerraumes und seiner Nachbarn. Die Fülle seiner Leistungen und seiner Publikationen, die gerade im letzten Jahrzehnt seines Lebens in den 5 Bänden „Ägäische Frühzeit“ (1976-1982) und in einigen anderen synoptischen Monographien kulminierten, wurden bereits an anderer Stelle gewürdigt ${ }^{1}$.

Erstmals trafen sich Schachermeyrs sprachliche Interessen mit seinen ägäischen Forschungen, als er 1929 seiner Habilitationsschrift „Etruskische Frühgeschichte" auch ein sprachliches Kapitel beigab. Ebenso richtete er bei seinen Studien über die frühgriechischen Kulturen stets große Aufmerksamkeit auf die vorgriechischen Orts- und Personennamen und auf anderes Sprachgut, das er als Hinweise auf altägäische Substrate in der gräzisierten Welt des südlichen Balkans ansah ${ }^{2}$. Er hatte auch die Kontroverse zwischen A. Evans und A. J. B. Wace um die historische Relevanz der Linear B-Texte verfolgt, und das Ringen des Michael Ventris um die Entzifferung dieser Schrift begleitete er als dessen Briefpartner. Wie Schachermeyr später beschrieb ${ }^{3}$, hatte er Ventris durchaus ermutigt, auf der Basis des Etruskischen an das Linear B heranzugehen. Es waren wohl seine profunden Kenntnisse des ägäischen Fundbestandes und seiner Implikationen, seine Erfahrung im Umgang mit frühen Sprachen und Inschriften, und nicht zuletzt ein ihm eigener, untrüglicher Instinkt für die richtigen Zusammenhänge, die ihn dann 1952/53 sofort die unerwartete und sensationelle Identifizierung des Linear B durch M. Ventris und J. Chadwick als Griechisch verstehen und akzeptieren ließen.

Ähnlich wie der große Wiener Gräzist Albin Lesky, blieb Fritz Schachermeyr in der Anerkennung dieser Entzifferung unbeeinflußbar, während anderswo Altphilologen und Althistoriker den Entzifferungsgegnern Glauben schenkten und aufatmend das Griechische wieder allein der klassischen Antike vorbehalten sehen wollten. Er nahm sogar aktiven Anteil an der Verteidigung der VentrisChadwick'schen Entzifferung ${ }^{4}$. Wenn er sich auch selbst nicht mehr imstande sah, die linguistische Arbeit an den Texten auf sich zu nehmen, so setzte er doch Schüler wie Klaus Wundsam oder mich selbst an dieses Material an. 1971 gründete Fritz Schachermeyr an der Österreichischen Akademie der

1 S. Deger-Jalkotzy, in: Anzeiger für die Altertumswissenschaft 41, 1988, 125-128. G. Dobesch, in: Almanach der Österreichischen Akademie der Wissenschaften für $1987 / 88,419-436$.

2 Vgl. F. Schachermeyrs Beiträge „Vor-Indo-Europäische Substrate und Indo-Europäische Zuwanderungen in der griechisch-anatolischen Frühzeit" sowie „Die alten Ortsnamen im ägäischen Raum", in: Acta of the 2nd International Colloquium on Aegean Prehistory, Athen 1972, 10-14 und 56-61.

${ }^{3}$ F. Schachermeyr, Mykene und Linear B-Schrift im Rahmen der Altertumsforschung, in: St. Hiller-O. Panagl, Die frühgriechischen Texte aus mykenischer Zeit, Darmstadt $1987^{2}, 1-18$.

${ }^{4}$ F. Schachermeyr, a. a. O. Vgl. auch Saeculum 10, 1958, 48 ff., 370 ff., $374 \mathrm{ff}$. 
Wissenschaften eine Kommission für Mykenische Forschung, als deren Aufgabe er die interdisziplinäre Erforschung der griechischen Frühzeit, und der mykenischen Welt im besonderen, definierte. Unter den Veröffentlichungen dieser Kommission nehmen Linear B-Studien keinen geringen Raum ein.

Wenn die Mykenologie heute einen eigenen Zweig der Altertumswissenschaft darstellt, so hatte Fritz Schachermeyr sicherlich einen großen Anteil daran. Es ist auch als sein Verdienst zu bezeichnen, daß Österreich an dieser Entwicklung vom Anfang an mitwirkte, indem Schachermeyr neben seinen Wiener Schülern auch die Salzburger Mykenologen Oswald Panagl und Stefan Hiller nach Kräften förderte.

Nicht nur als Erforscher der archäologischen Materialien, sondern auch als Förderer der Studien an den Linear B-Texten und an den übrigen, unentzifferten Schriften des Ägäisraumes, war Fritz Schachermeyr international berühmt und anerkannt. Er war Teilnehmer an den Mykenologischen Kolloquien und der Vertreter Österreichs im CIPEM. Die Herausgeber des „Kadmos“ konsultierten ihn nicht nur für die Beurteilung von Manuskripten: Von der Gründung dieser Zeitschrift an gehörte Fritz Schachermeyr selbst zu ihren Mitherausgebern.

Es ist also geziemend, daß „Kadmos“ in die Reihe derer eintritt, die den Hingang Fritz Schachermeyrs als einen schweren Verlust beklagen. Als großer Erforscher der altägäischen Kulturen wird er unvergessen bleiben.

Sigrid DEger-JALKotzy 